\title{
Why this new journal?
}

\author{
Kenneth Nugent, MD
}

The development of a medical journal has multiple potential benefits. The demand for journal space continues to increase, and many journals state that they can only publish $20 \%$ of the submitted manuscripts. Medical journals in United States attract an international audience of readers and authors. The residency review committee for internal medicine expects key faculty to have scholarly activity. This promotes an academic environment in both residencies and fellowships, and ideally most faculty members should try to submit one scholarly activity for publication per year. Consequently, we think there is a need for additional journals.

Electronic journals provide an opportunity for scholarship at all levels of medical education, including medical students, residents, and fellows. Medical scholarship should enhance clinical thinking and improve both written and oral communication. It should also enhance critical analytic skills of reviewers and editors and provide a better understanding of the information we use for daily patient care. New journals may try different formats which potentially expand the scope of academic activity. We hope that this journal expands the scholarly activity at our school and other institutions and helps start academic careers.

I need to acknowledge the efforts of production editors and their essential work during the developmental phase of this journal. These individuals include Ornwadee Siangpraipunt MD, Nopakoon Nantsupawat, MD, Rie Okamura, RN, Connie Nugent, MLS, and NavadonKhunlertgit, M ENG. We also thank the Department of Internal Medicine (Texas Tech University Health Sciences Center) and University Medical Center in Lubbock, TX, for financial support.The Southwest Respiratory and Critical Care
Chronicles is a nonprofit corporation with modest resources. We will eventually charge for some of these publication types, but we will try to keep the costs low. We would appreciate contributions (tax deductible) to help with our operating costs.

We want to publish original articles, review articles, and case reports. In addition, we will publish short updates on pulmonary and ICU topics, interviews, images, and letters. Please review the articles in the first issue and provide constructive feedback. We welcome any submissions related to respiratory and critical medicine. In addition, we are very interested in articles and commentary on medicine and public policy.
Author Contact Information: kenneth.nugent@ttuhsc.edu DOI: 10.12746/swrccc2013.0101.001 